\title{
Emotion: More like Action than Perception
}

\author{
Hichem Naar $^{1}$ D
}

Received: 12 November 2018 / Accepted: 7 September 2020 / Published online: 27 October 2020

(c) The Author(s) 2020

\begin{abstract}
Although some still advance reductive accounts of emotions-according to which they fall under a more familiar type of mental state-contemporary philosophers tend to agree that emotions probably constitute their own kind of mental state. Agreeing with this claim, however, is compatible with attempting to find commonalities between emotions and better understood things. According to the advocates of the so-called 'perceptual analogy', thinking of emotion in terms of perception can fruitfully advance our understanding even though emotion may not be reducible to ordinary perception. In this paper, I spell out and motivate a different analogy-that between emotion and action - an analogy which I think can do some important theoretical work. In particular, it constitutes a theoretically fruitful way to think about core aspects of emotions and might in fact be employed to provide a better account of certain aspects of emotions than the one based on the perceptual analogy. Emotions might not be a matter of seeing the world a certain way, but a matter of behaving internally in response to it. In a slogan form: Emotion is the inward counterpart of bodily movement.
\end{abstract}

\section{Introduction}

Although some still advance a reductive account of emotions-according to which emotion falls under a better understood type of mental state (e.g., judgment, desire, etc. ${ }^{1}$ - contemporary philosophers working on emotion tend to agree that emotions probably constitute their own kind of mental state (D'Arms and Jacobson 2003; de Sousa 1987; Döring 2007; Goldie 2000; Greenspan 1988; Helm 2001; Roberts 2003). But even if reduction is not to be expected, there is a tendency to account for emotions in terms which are nonetheless familiar. Many philosophers indeed tend to think of emotions as representations, that is, roughly, as mental states with a

\footnotetext{
1 Of course, there are accounts that aim to reduce mental states to physical states (e.g., brain states). I would like to stay neutral on the big issue of physicalism.

Hichem Naar

hm.naar@gmail.com

1 University of Duisburg-Essen, Essen, Germany
} 
content with an object-property structure (i.e., they attribute properties to objects). ${ }^{2}$ Moreover, some theorists tend to think of emotions as epistemically significant in some way; emotions, as it were, are forms of awareness of the world (Tappolet 2016, 30). To bring out these features in a systematic way-and given the absence of a plausible reduction - a number of theorists have drawn an analogy between emotion and some better understood mental state. According to the advocates of the socalled 'Perceptual Analogy' (e.g., Deonna 2006; de Sousa 1987; Döring 2003, 2007; Milona 2016; Pelser 2014; Roberts 2013; Tappolet 2000, 2016), thinking of emotions in terms of perception can fruitfully advance our understanding of their core aspects even though they may not be reducible to ordinary perception. ${ }^{3}$ According to Christine Tappolet, the Perceptual Analogy is the main reason we should accept the claim that emotions are genuine perceptual states of some sort (though, perhaps, of a different kind from ordinary, sensory perception). She writes:

The argument for the perceptual account of emotions is an argument by analogy. It is based on the observation that emotions and sensory perception, which can be taken to be paradigm cases of perceptual experiences, share a number of important features. (Tappolet 2012, 207).

In a similar vein, several writers draw an analogy between emotion and sensory perception to support the claim that emotion should be understood as perceptionlike in various respects. Here is Sabine Döring:

On my account, $[\ldots]$ an emotion's intentionality is best understood by analogy with perception. This is at least so if it is agreed that a perception also possesses both phenomenology and intentionality, and that its intentional content is also part of its conscious, subjective character [...]. (Döring 2007, 376)

Another advocate of the Perceptual Analogy, Michael Milona writes:

The thought common to [advocates of the Perceptual Analogy] is that just as a visual experiences [sic] can present, say, shape properties, certain affective

\footnotetext{
2 I borrow this rough characterization of representational states from Mendelovici (2013), although, as she convincingly argues, it is unclear that all representations have this structure. That said, I take it that most people engaged in the debate over the nature of emotion would be happy with it.

3 Some perceptualists are happy to claim that emotions are perceptual experiences of some kind, but since they would also admit that emotions are different from ordinary perception in some important respects, they might also admit that emotions are not completely reducible to the latter. In any case, the argument in the text applies equally well to those theorists who defend a full-blown reduction of emotion to perception on the basis of the Perceptual Analogy. See, e.g., Tappolet (2016) who claims that emotions are perceptions (on a 'liberal' conception of perception, pp. 29-30), although she concedes that emotions are disanalogous to ordinary perception in various respects (pp. 24-27). An early advocate of the analogy, Ronald de Sousa explicitly claims that "the analogy is not so close as to warrant the assimilation of emotions to perception, any more than to beliefs or desires." $(1987,149)$.
} 
experiences can present evaluative properties. If emotions [...] involve presentations of value, then [...] perceptualists can argue that there is an explanation for why certain affective experiences rationalize evaluative beliefs. Just as perceptual experiences rationalize empirical beliefs in virtue of presenting reality as being some way, so too do certain of our emotional experiences. (Milona 2016, 899-900)

Given that emotion and perception do share some features, it is not difficult to see the attraction of the Perceptual Analogy. Emotion and perception are both intentional mental states with a phenomenal character, and both are often characterized as things we undergo rather than things we do. Moreover, emotion and perception both seem capable of conflicting with certain beliefs or judgments. Just like I can see the two lines of the Müller-Lyer illusion as of different lengths while believing that they are in fact of equal length, I can be afraid of the dog while believing that she is not dangerous. Emotion and perception can also go wrong: just like my perceptual experience as of a blue car is in some sense inappropriate when there is in fact no blue car in front of me, my indignation towards someone for insulting me is in some sense inappropriate if what that person said was in fact not offensive. This suggests, in turn, that the appropriateness conditions of emotions will be couched in broadly evaluative or normative terms (e.g., in terms of offensiveness, admirability, dangerousness, etc.). It is crucial to note that, beyond noting these uncontroversial points of analogy, the perceptualist usually has an epistemological agenda, and subscribes to a view of perception on which perception is a source of knowledge and/or justified belief. As a result, they generally claim that emotion and perception share a further feature - that of being epistemically special in some way-thereby recruiting the Perceptual Analogy to argue for more controversial claims about emotions.

The goal of this paper is to show that we should make room for another analogy which I think is in some ways more promising than the Perceptual Analogy; at any rate, it should be seen as a serious competitor to it. It is an analogy between emotion and action. The action model says that emotions are not so much a matter of seeing the world a certain way, but a matter of behaving internally in response to it. In a slogan form: Emotion is the inward counterpart of bodily movement. ${ }^{4}$

Besides providing an interesting way of conceiving of the emotions and their connection to the world, I think that, insofar as the Action Analogy provides a plausible account of the central features that motivate the Perceptual Analogy in the first place, it constitutes a serious threat to its alleged theoretical force. In particular, it weakens the force of the claim-based on a deployment of the Perceptual Analogy - that emotions have the epistemically special character of ordinary perception. Given that it is arguably not in the nature of action in general to put us in touch with aspects of the world, i.e. actions in general are not epistemically special (at least the

\footnotetext{
4 This slogan is in some way misleading, as the intended analogy is between emotion and action (or perhaps behavior more generally), rather than between emotion and the bodily movement associated with action. The slogan, however, is meant to avoid giving the impression that the view in question is that emotions are mental actions of some kind. It also draw our attention on the question of what turns a mere internal/bodily change into an emotion, a similar way it is common to ask what is needed for a bodily movement to constitute a full-blown action.
} 
way perception is), the claim that emotions play some special kind of epistemological role becomes something we have no particular reason to hold (unless, perhaps, it is shown that the actions to which emotions are analogous are themselves epistemically special). ${ }^{5}$

On top of that, the Action Analogy, properly construed, has the potential to account for further features we ascribe to emotions prior to inquiry, making in turn the Perceptual Analogy undermotivated. In addition, the Action Analogy has the same resources as the Perceptual Analogy to face various worries which might be subjected to it. The upshot will be that the Action Analogy-in its reliance on action theory-not only (1) provides unexplored resources for emotion theorists, it may also (2) make the more dominant Perceptual Analogy at best unnecessary (in that we may not need it to elucidate the core aspects of emotions) and at worst misleading (insofar as reliance on it may have led theorists to the wrong account of core features of emotions). Although I will spend much of this paper motivating (1), it should become clear that the possibility of (2) gives an important reason to advocates of the Perceptual Analogy to seriously engage with future developments of the Action Analogy.

Here's the plan of the paper. In Sects. 2 and 3, I introduce the Perceptual Analogy, clarify what the analogy is supposed to achieve, and rehearse some common problems for the perceptual view of emotions defended on the basis of the Perceptual Analogy. In Sect. 4, I introduce and motivate the Action Analogy as an alternative to the Perceptual Analogy.

\section{The Perceptual Analogy}

To motivate their analogy, perceptualists ${ }^{6}$ typically start by drawing our attention to largely pre-theoretical features theorists would typically agree-at least prior to inquiry-emotion and perception seem to share, and that most would take as plausible data points; call such features relatively uncontroversial features ('RU features'). ${ }^{7}$ Here are some examples: (1) intentionality: both emotion and perception

\footnotetext{
5 It is doubtful, however, that any action can play an epistemic role as fundamental as the one commonly thought to be played by perception. Of course, actions can lead to knowledge-in searching for the newspaper, and in reading it, I end up knowing a lot of things about the world. It is however not the action per se that gives us access to the relevant information, but our perceptual systems combined with our mastery of language, our ability to draw inferences, and so on. At any rate, the view that certain actions are basic ways of accessing the world (like perception is supposed to be in our context) is hard to make sense of.

6 This is especially clear of Tappolet, who argues most explicitly that a systematic analogy between emotion and perception gives us a strong reason to claim that emotion is perception-like in some fundamental way. See also Milona (2016), who seems to think that the best way to defend perceptualism about emotions is to pursue a parallel study of emotion and perception, to "go beyond the initial, minimal analogy with perception" by taking the analogy "seriously" (998). In the following, the focus will be on the general research program that philosophers such as Tappolet and Milona advocate.

7 I call them 'relatively uncontroversial' because there are always going to be some people who will reject them. What matters here is that, at least for dialectical purposes, the people in the debate are likely to take the relevant attributions as starting point even if, down the line, they may reject them.
} 
are intentional mental states-they are always about something; (2) phenomenology: both have phenomenal character-there is something it is like to be angry with someone, just as there is something it is like to have a perceptual experience as of something red; (3) passivity: emotion and perception are things we undergo, things that happen to us, rather than things that we actively do; (4) conflict with belief: emotion and perception can conflict with certain beliefs or judgments; (5) appropriateness: there are conditions under which both emotion and perception can go right, couched in evaluative terms.

The perceptualist does not rest content with noting these uncontroversial, and rather coarse-grained, points of similarity. They attempt to account for emotion's RU features by helping themselves to what they take to be plausible accounts of the associated features of perception. ${ }^{8}$ In the literature, this sort of strategy seems to have been deployed, at least implicitly, to account for at least three of the features we pre-theoretically ascribe to emotions: (1) intentionality; (4) conflict with belief; (5) appropriateness. Consider intentionality. Emotions are always about something or other-they always have an intentional object. Perception, clearly, has this feature too. Now, suppose that the best way to account for the intentionality of perception is in terms of attributing to perceptual experiences a representational content with an object-property structure. Then we have a natural way of capturing the intentionality of emotions in an analogous way by claiming that emotions represent their objects as having certain (according the perceptualist, evaluative) ${ }^{9}$ properties. One could then use the resources provided in the philosophy of perception to spell out this account in a satisfactory way.

Given the perceptualist's account of the intentionality of emotions, it is not difficult to see how they would account for appropriateness. When a perceptual experience goes right, this means that the representation that it involves is veridical; and if it goes wrong, this means that the representation is non-veridical. In other words, when a perceptual experience is veridical, the world is really the way the perceptual experience represents it to be. As a result, the sense in which a perceptual experience can be appropriate or inappropriate is representational; appropriateness conditions for perception should be spelled out in terms of representational accuracy. Now, we all agree that emotion can in some sense go right or wrong too depending on whether or not its intentional object instantiates a certain evaluative or normative property. If the Perceptual Analogy is on the right track, we should cash out emotion's appropriateness conditions in terms of representational adequacy (in particular

\footnotetext{
${ }^{8}$ One might distinguish between modest and ambitious ways to employ the Perceptual Analogy, or to be a perceptualist. Whereas the modest perceptualist rests content with noting various features that emotion and perception have in common (at a certain level of description), the ambitious perceptualist intends to use the Perceptual Analogy as a way to reach a genuine account of the various aspects of emotions. It should be obvious that the modest perceptualist view, to the extent that it is a 'view' at all, is too modest to be a subject of controversy, which is why most, if not all, perceptualists are ambitious. The focus in the text will therefore be on perceptualism of the ambitious sort.

9 One reason for thinking that emotions represent evaluative properties is that, given the tight conceptual connection between emotion and value, evaluative properties are one of the most natural candidates of things emotions might represent.
} 
in terms of whether the emotion correctly represents its intentional object as instantiating the relevant evaluative or normative property).

Finally, perceptual experiences can conflict with certain beliefs in virtue of having a certain representational content which conflict with these beliefs' content, as in the case of perceptual illusions. If emotions are analogous to perception in the way they relate to the world, then the sense in which an emotion can conflict with belief (in particular evaluative belief) may be elucidated in terms of a certain kind of (evaluative) illusion.

At this stage, it is important to note that the claims that emotions have representational content, that they can be veridical or non-veridical, and that they can conflict with belief in a way analogous to perceptual illusions are claims that $g o$ beyond the claims of the pre-theoretical sort we started with. The perceptualist's argument, indeed, is that the relevant theoretical claims constitute the best way to elucidate various platitudes about emotions of the sort we find in (1)-(5). Call the features the perceptualist attributes to emotion-such as emotion's being representational, having perception-like accuracy conditions, and so on-as a result of considerations of this sort theoretical features, which contrast with the RU features of the sort involved in (1)-(5). By contrast with RU features, theoretical features are those features we would not attribute to emotions prior to inquiry; roughly put, they are more on the 'output' side than the 'input' side of our investigation. So even though we may initially agree with the perceptualist's list of RU features (i.e., even though we may accept the claims the perceptualist takes to be platitudinous), we may find problems in the way the perceptualist elucidates them, thus rejecting the perceptualist's main support for the claim that emotions have the relevant theoretical properties. In fact, as we will see in Sect. 3.2, this is a standard way to reject the perceptual account of emotions.

In light of this distinction, it is crucial to see that the claim that emotion is epistemically special a similar way perception is is something that arguably falls out of the Perceptual Analogy ${ }^{10}$ rather than a claim that we ought to accept prior to inquiry. Presumably, it is not a platitude that an emotion is a basic way of being aware of certain aspects of the world. The relevant feature-being epistemically special in the way that perception is-is therefore a theoretical feature. ${ }^{11}$ At this stage, one might wonder how the perceptualist may arrive at the claim that emotions are epistemically special in the way perception is. Although perceptualists are generally not completely explicit about the line of reasoning that should lead to this claim, there are arguably two main ways to go.

The first is to start by noting certain points of analogy between emotion and perception. For instance, there is a sense in which both emotion and perception have

\footnotetext{
${ }^{10}$ Although, of course, it need not, depending on how the analogy is pursued. But it is standard to think that perception is quite distinctive from an epistemological perspective-e.g., it is a basic source of knowledge.

11 A further theoretical feature attributed to emotion has to do with the kind of content it has. According to some perceptualists (e.g., Tappolet 2016), the content of emotion is non-conceptual. See below.
} 
features involved in (1)-(5): emotion and perception are both intentional, conscious, and passive, and they both can conflict with belief and go right or wrong. Finding these points of analogy striking, we might then feel confident that the relevant features will be accounted for a similar way in both cases, by appealing to theoretical features they share. If these features involve ones that plausibly ground perception's epistemic specialness, then we should expect that, possessing them too, emotions will turn out epistemically special as well. ${ }^{12}$ We would then hope to go on to develop an account of the relevant kind of epistemic specialness. ${ }^{13}$

The fact that emotion and perception share a number of RU features may ground confidence in the possibility that they will be elucidated the same way. But until it is shown that this is possible, the first strategy only gives the perceptualist some hope that their epistemological agenda can be successfully carried out. The second strategy, however, attempts to secure the epistemic specialness more directly. It consists in accounting for a particular RU feature shared by emotion and perception by appealing to a theoretical feature that strongly suggests a similar epistemic profile. For instance, Tappolet (2016) claims that the intentionality of both emotion and perception should be explained in terms of their both having some sort of (non-conceptual) representational content that allows perception to be epistemically special in some way. If this is the case, then, absent some countervailing factors, we should expect emotion to be epistemically special a similar way.

Note that the first and second strategies are related in an important way. It is because emotion and perception are sufficiently alike in general that the claim that they share the very feature that makes perception epistemically special becomes particularly plausible. ${ }^{14}$ And this is indeed how Tappolet ends up with her final view: by first motivating a general analogy between perception and emotion, and then arguing that one of the points of analogy should be accounted for a similar way. Unless at least some general analogy holds between emotion and perception, the claim that emotion and perception share a highly significant epistemic feature would seem unmotivated. For as I will suggest (see Sect. 4.4), it is a mistake to treat emotion's

\footnotetext{
12 Tappolet (2016) seems to be the most explicit about this: "In so far as emotions have these features [for Tappolet, phenomenal properties, automaticity, world-guidedness, correctness conditions, and informational encapsulation], nothing bars us from making the claim that emotions involve a genuine kind of perception" (30), whereby perception is conceived of as "a kind of awareness of things and their qualities" (29).

13 It should be noted that a perceptualist need not attribute the relevant epistemological feature to emotions, either because they may not take perceptual experiences to have that feature or, more plausibly, because they may take emotions to be disanalogous to perceptual experiences in this respect. I take it though that this sort of move-even if justified-would render the Perceptual Analogy much less philosophically exciting than it is.

14 How general should the similarity be? It is difficult to say. In the following, I will assume that an interesting analogy between emotion and perception should include more than one or two points of similarity. It should be such that one should find it striking. If emotion and perception were only similar because both are intentional mental states with phenomenology, this would not be enough to make the claim that emotion is best modelled on perception look particularly attractive. I take it that advocates of the Perceptual Analogy have reasons to want their analogy to be suitably general. This is indeed a natural way to understand the idea of 'taking the perceptual analogy seriously' (Milona 2016). Emotion should be analogous to perception in enough ways so that it is better analogized to perception rather than to some other kind of response such as belief, desire, or action. Thanks to a reviewer for discussion.
} 
core aspects as independent units to be elucidated separately; rather, an adequate account of emotion should capture the important connections that hold between them. At any rate, this should be the aim of anyone-including the perceptualist and the advocate of the action model later defended-attempting to understand emotion in general by analogy with some other kind of entity.

A natural way to reject the perceptual model is to resist the claim that there is an interesting general analogy between emotion and perception, thereby removing any clear (analogy-based) ${ }^{15}$ motivation for the project of establishing the more specific claim that emotion and perception are alike epistemologically.

There are two ways to undermine the perceptualist's project in this way, both of which have been pursued in the literature. The first is to show that emotion has RU features that perception does not have. The second is to argue that the perceptual model provides an inadequate account of emotion's RU features in such a way that similarities between emotion and perception held important by the perceptualist are shown to be only apparent. In the next section, I will briefly discuss common ways of pursuing these two strategies. These strategies are meant to cast doubt on the claim that there is a theoretically fruitful general analogy between emotion and perception, thereby removing any clear motivation for pursuing the claim that emotions are epistemically special the way perception is. Indeed, if a plausible account of the relevant features that does not force us to accept the epistemic claim is available, then we will lack any positive reason to accept it. ${ }^{16}$ As I will suggest, however, the dialectical force of these attacks is limited, as various moves are available to the perceptualist.

This is where the Action Analogy comes in. In Sect. 4, I argue, using the perceptualist's general style of argument, that the Action Analogy is a promising way to elucidate features (1)-(5) - and other RU features of emotion introduced in Sect. 3.1-which, if it worked, would remove any clear motivation for the theoretical claim that emotions are epistemically special the way perception is (and any other theoretical claim motivated on the basis of the Perceptual Analogy). It does so by making possible plausible accounts of core features of emotions that do

\footnotetext{
15 As noted by a reviewer, there are arguments for the perceptualist picture that do not appeal to any general analogy between emotion and perception. For instance, one might argue that emotional experience is perception-like (Furtak 2018; Mun 2019; Pelser 2014, 108; see also Cowan 2016, 60). For a recent argument that emotional experience is in fact disanalogous from perceptual experience, see Mitchell (2019). For a sustained argument that emotional intentionality cannot be assimilated to the intentionality of 'receptive' mental states like perception, see Müller (2019).

16 This point is important to stress, as one might think that to reject the Perceptual Analogy, one must refute the claims people make on its basis, i.e. show them to be false. A much more realistic way to critically engage with them, however, is to provide a picture that removes any clear motivation for them. For all we know, it might be true-and it might even be nice (given the problems facing the alternative epistemological accounts of value, say) - that emotion is a "kind of awareness" of, a "form of openness" to, value (Tappolet 2016, 29). It's just that, given the Action Analogy as promising alternative, the Perceptual Analogy should not rationally compel us to believe it.
} 
not give us any special reason to take the perceptualist's epistemic hypothesis seriously. In particular, it makes possible an account of emotion's intentionality that does not rely on the claim that emotions have the sort of content involved in the case of perception. ${ }^{17}$

If this is on the right track, this is a significant result, for the Perceptual Analogy is so distinctive (and popular) in great part because of its epistemological upshot. Of course, the argument in what follows should only be seen as a preliminary defense of the Action Analogy, for what it says is precisely that a systematic parallel study of emotion and certain actions may be a fruitful way of shedding light on the nature of emotion. Although this paper should be seen as a promissory note, however, I hope it will give enough of an idea of how promising the Action Analogy is as a systematic way to approach the emotions. ${ }^{18}$

\section{Problems with the Perceptual Analogy}

There are two common ways to resist the Perceptual Analogy: (1) pointing to RU features that emotion has but perception lacks (at least prima facie); (2) challenge the way the perceptualist understands RU features emotion apparently shares with perception. As this is not the place to fully assess the Perceptual Analogy, let us briefly discuss a sample of them in turn.

\subsection{Differences Between Emotion and Perception}

There are at least two respects emotion seems to differ from perception in a clear way. Given that they are likely to be accepted by many people prior to inquiry, the following features plausibly count as RU features. To avoid the charge that I

\footnotetext{
17 Admittedly, the strategy pursued here would not be enough to undermine direct arguments for modelling the intentionality of emotion on the intentionality of perception, as these arguments purport to work irrespective of whether emotion and perception are alike in other respects. Although I do not have objections to such arguments as far as they go, I find it unlikely that they can be reasonably put forward unless one thinks that emotion and perception share other features. For without this assumption, it becomes possible for the opponent to insist that their differences are sufficiently important to make us suspicious of any such direct argument. In any case, this is not a common strategy among perceptualists (Tappolet, for one, is quite explicit, see above), though see the references in Ft.15 to perceptualist arguments that appeal to analogy-independent considerations such as facts about emotional experience, and to skeptical replies.

18 It might turn out, down the line, that emotion is epistemically special in some way or other even if it is best modelled on action. This is a question this paper will leave open, its core target being the Perceptual Analogy and the more specific claims that are motivated on its basis.
} 
pack controversial theoretical claims into my characterization of such features, I'll describe them in a way that should be acceptable to many. ${ }^{19}$

\section{Cognitive dependence}

By contrast with perception, emotion is not an independent way of accessing its intentional object. In order to be afraid of something, I first need to see that thing, or to believe that it is there, or at least to think of it in some way. In other words, I need to have a prior grasp of it, a grasp which is not given by my fear. The fact that emotions depend on cognitive states like this - that they have cognitive bases-puts them in contrast with perception (Deonna and Teroni 2012, 2014). ${ }^{20}$

The fact that emotions have cognitive bases, furthermore seems to allow them to have a wide variety of intentional objects. Indeed, the intentional object of an emotion need not be perceptually present. It can be far in the past or the future. It can be purely imaginary. It can be abstract. None of these objects seem to be obviously represented in ordinary sensory perception (Deonna and Teroni 2014). ${ }^{21}$

\section{Reasons \& Reasons-Responsiveness}

In contrast with perception, emotion is the kind of thing for which we have normative reasons, and for which we can be criticized (Brady 2013). ${ }^{22}$ Indeed, emotions

\footnotetext{
19 As noted by a reviewer, to the extent that committed perceptualists may reject the relevant claims, the latter are not completely theory-neutral. I do not want to deny that some perceptualists may not be moved by the broadly intuitive considerations that have been put forward against their view. And, of course, there are perceptualists whose final view denies, e.g., that emotions are reasons-responsive. Perhaps, indeed, this is, from their perspective, the right thing to say. The point remains that the relevant intuitive considerations are taken seriously by the perceptualist's opponents, and are not undermined by the mere fact that committed perceptualists may reject them. In fact, the problems raised here are ones perceptualists have tried to answer in a number of ways (see Sect. 3.3). Tappolet (2016), for one, takes seriously all the problems presented here. At any rate, the problems discussed in this subsection and the next are ones the perceptualist's opponents have themselves raised. So, even supposing these problems should not move the perceptualist (given their commitments), the project of this paper is barely undermined: if one is sympathetic to the considerations presented here, one should find the Action Analogy more theoretically attractive than the Perceptual Analogy. Although I hope that the Action Analogy is something the perceptualist themselves should take seriously, it would still be an achievement if it was shown to be a good alternative for those dissatisfied with perceptualism.

20 Although she ultimately denies its significance (see Sect. 3.3), Tappolet accepts this point of disanalogy between emotion and perception: "The dependence on cognitive bases is one of the factors that explain why emotional experiences differ from sensory experiences.” $(2016,26)$.

21 Although the phenomenon of cognitive dependence has sometimes been thought to constitute a blow against the Perceptual Analogy, I think there are ways for the perceptualist to accommodate it by analogizing emotions and specific forms of perception, though the resulting story leads to some potentially controversial claims (Milona and Naar 2020). See also Furtak (2018) and Mun (2019).

22 Although, again, ultimately denying the significance of this feature (3.3), Tappolet concurs: "in typical cases the question arises as to whether or not the emotion is justified. Suppose that in answer to the question "Why do you find Sarah admirable?" I simply say that I admire Sarah. This answer will surely appear unsatisfactory and I will immediately be asked why I admire Sarah. This admittedly makes for a difference between emotions and sensory experiences." $(2016,39)$.
} 
are not only things that admit of justification; they appear to be responsive to reasons (insofar as the agent is rational) a way that perception doesn't seem to be, at least prima facie. As Solomon notes,

[I]f you criticize my anger at John by maintaining that he has not wronged me, you may conclude that my anger is unreasonable, unfair, and perhaps unbecoming. But if you should convince me that John has not wronged me, I do not simply conclude that my anger is unreasonable, unfair, or unbecoming. I cease to be angry. (Solomon 1973, 31)

One might resist the claim that perception is never reasons-responsive. In a sense, indeed, perception is a matter of registering certain aspects of the world. A good perceptual system, one might say, is a system that responds properly to the world. This, however, is not the sense of reasons-responsiveness people have in mind when they contrast emotion and perception in terms of this feature. What they have in mind is the idea that there are normative reasons to which emotions respond. The notion of reasons-responsiveness thus entails that any genuinely reasons-responsive response will be favored by normative reasons. The crucial claim then is that emotion is, while perception is not, supported by normative reasons. And given the plausible claim that mental states that are supported by normative reasons must be capable of being responsive to them (Kiesewetter 2017; Lord 2018), it seems safe to assume that emotions are, while perception isn't, responsive to reasons. ${ }^{23}$

\subsection{Troubles with the Perceptualist Understanding of Certain Similarities Between Emotion and Perception}

The foregoing might suggest that, given that emotion and perception are disanalogous in various respects, it is at least unclear why we should nonetheless be confident that, despite these differences, emotion and perception are still alike enough to secure an epistemic similarity between them. The perceptualist, however, might insist that so long as the features that motivate the general analogy between emotion and perception (namely (1)-(5)) are left untouched, they are warranted in being hopeful that emotion and perception will be, down the line, epistemically similar. Unfortunately, as noted by various authors, there are reasons for thinking that the perceptualist's theoretical understanding of at least two of these features (namely (4) conflict with belief and (5) appropriateness) is mistaken.

\section{Conflict with Belief}

It is undeniable that there is a sense in which emotion can conflict with belief, just like there is a sense in which a perceptual experience can conflict with belief. So, emotion

\footnotetext{
23 Could there be normative reasons for mental states that are incapable of responding to them? Maybe. Even if this is a genuine possibility, this does not undermine the plausibility of the claim that there are normative reasons for emotion but not for perception, and that some cases of emotion formation or eradication appear to be cases of reasons-responsiveness.
} 
and perception appear to share a RU feature. But one might worry that the senses in which emotion and perception can conflict with belief are not the same. If we look more closely into what is involved in so-called 'recalcitrant emotions' (i.e., emotions which conflict with associated evaluative beliefs), we will see that an account of them modelled on perceptual illusions is not going to work. Indeed, it is very plausible that a recalcitrant emotion can be irrational in a way that a perceptual experience cannot be, suggesting that the Perceptual Analogy fails to capture what we really had in mind when we claimed that emotion can conflict with evaluative belief. In the grip of intense fear at the view of a spider, I may judge that the spider is not dangerous. So, there is a conflict between my fear and my judgment. What we have in mind when we approach cases like this, however, is something much more specific, namely that the conflict is a rational conflict; I am in some sense irrational in continuing to feel fear in the face of what I take to constitute no threat. And this is different from a case where I am aware of being in the grip of a perceptual illusion, where intuitively I am not irrational. The real RU feature we should aim to account for, therefore, is, not that there can be conflicts between emotion and belief simpliciter, but that there can be rational conflicts between them (Benbaji 2013; Helm 2001). ${ }^{24}$

\section{Appropriateness}

As noted by perceptualists, emotions can be assessed in a variety of ways, but there is a way which stands out conceptually. There are appropriateness conditions which apply to emotions in virtue of the kind of thing they are. For instance, although laughing at a joke at a funeral may be inappropriate all things considered, we may still think that laughing would 'fit' the joke given that it is genuinely funny (D'Arms and Jacobson 2000). ${ }^{25}$ Following Dokic and Lemaire (2015), let's call appropriateness conditions in the 'fitting' sense intrinsic correctness conditions. ${ }^{26}$ An emotion type, then, has intrinsic correctness conditions in virtue of the kind of thing it is, in virtue of its nature. Importantly, these conditions will involve evaluative or normative properties we can associate a priori with each emotion type. Fear is fitting just in case its object is dangerous, admiration is fitting just in case its object is admirable,

\footnotetext{
24 Elsewhere (Naar 2019), I argue that an important subset of emotions-notably the emotions of animals and the various knee-jerk affective responses we instantiate-are outside the purview of rationality; they are arational. If this is right, then it won't be true that every conflict between emotion and judgment is a rational conflict. However, so long as some conflicts are rational conflicts, a perceptualist faces the problem discussed in the text, given that it is standard to think that perception is not the sort of thing that enters in genuine rational conflicts (though, again, this is something committed perceptualists might deny-see Ft.19). To anticipate the Action Analogy, the arational emotions may be best modelled on reflex responses rather than actions proper, in which case the discussion in the text would not directly apply to them. Still, the fact that we can easily find an analogue in the behavioral case should give us some confidence that different classes of emotion will correspond to distinct classes of behavioral responses. For the sake of simplicity, in what follows I will leave aside the possible case of arational emotion.

25 The example is from Dokic and Lemaire (2015 271).

26 See also Kenny (1963).
} 
and so on and so forth. Extrinsic correctness conditions, by contrast, are conditions which do not involve normative or evaluative properties that are conceptually tied to emotion types. For instance, the fact that one will feel better if one stops feeling sad might be a good reason to stop feeling sad, even though sadness may be appropriate or fitting in the relevant situation.

A popular way of accounting for intrinsic correctness conditions is by claiming that emotions have evaluative contents. According to a version of the so-called cognitive theory of emotions, for instance, emotions are evaluative judgments, and intrinsic correctness conditions are the conditions under which they-as judgments - are true. Given the important problems which are thought to plague the judgment theory, ${ }^{27}$ the perceptualist account looks like a better way to defend the claim that emotions have evaluative contents. Given the Perceptual Analogy, intrinsic appropriate conditions should now be accounted for, not in terms of truth (like on the cognitive theory), but in terms of a notion which applies to perceptual experiences, namely representational adequacy (or veridicality). ${ }^{28}$ So the Perceptual Analogy seems to have the resources to account for a further RU feature of emotion, namely their having intrinsic correctness conditions couched in certain evaluative or normative terms (Tappolet 2016). ${ }^{29}$

Now, it is clear that there is a sense in which an emotion can go right or wrong, and that there is a sense in which perception can go right or wrong. So, at a rather coarse-grained level, emotion and perception share the feature of being appropriate, correct, or fitting (assuming a coarse-grained understanding of these notions). The question, however, is whether the senses in which emotion and perception can be appropriate are in fact the same (or sufficiently close), and should therefore be accounted for a similar way. And I think it very plausible that, when it comes to intrinsic appropriateness, emotion and perception are disanologous. The question is, what do we mean when we say that the intentional object instantiates the normative property that reveals it to be fitting, that is, what do we mean when we say that an object is fearsome or admirable? It seems that what we say is, inter alia, that the object merits a certain kind of emotional response, namely fear, anger, or admiration. The RU feature we have in mind when we speak about appropriateness, therefore, is one whose elucidation will involve a seemingly normative notion such as merit, ${ }^{30}$ which gives us the following, more fine-grained RU feature: $\left(5^{*}\right)$ appropriateness as merit: emotions can be appropriate or inappropriate in the sense of being merited or not merited. Notice now that, if we replace (5) with $\left(5^{*}\right)$, it looks like we lose a clear point of analogy the perceptualist posited between emotion and perception. If perception can be the sort of thing to be appropriate or inappropriate,

\footnotetext{
27 For a classic critique, see Deigh (1994). For a recent critique, see Scarantino (2010). For a recent defense of the view against criticisms stemming from overintellectualization, see (Naar 2019). For a discussion, see Deonna and Teroni (2012) and Furtak (2010).

28 This is of course assuming that perception is a representational state, something most, if not all, perceptualists about emotion do.

29 For a helpful discussion, see Dokic and Lemaire (2015).

30 See Secfoott. 4.3 for the claim that appropriateness/fittingness/merit is standardly understood in normative terms, and for references.
} 
indeed, it is not-or at least not obviously-in the sense of being merited or not merited; rather, as we have seen, it is in the sense of representing or not representing the world accurately. If this is right, then the distinctive sense in which emotions can be appropriate or inappropriate is not something the perceptualist can point to as support for their epistemic claim. We seem to have lost our main reason to attribute representational content to emotions. ${ }^{31}$

\subsection{Possible Moves}

In response to these objections to their reliance on the Perceptual Analogy to secure their epistemic claim, the perceptualist can resort to three possible moves. ${ }^{32}$ First, one may simply reject the alleged platitudes laid out in 3.1, or reformulate them in a perceptualist-friendly way. ${ }^{33}$ Second, one may adopt a more liberal conception of perception, or argue that there is $a$ conception of perception out there which captures the additional RU features (including the new ones-such as rational conflict with belief and appropriateness as merit-specified in 3.2). Finally, a more modest proposal is to embrace the disanalogies in question, but claim that they are not as deep as the opponent claims them to be, failing to cast doubt on the core of the perceptual model, such as its epistemological upshots (Tappolet 2016, 27; see also Pelser 2014, 109).

Note that the perceptualist has a greater burden than it may have initially appeared. What started out as a helpful analogy became the subject of theoretical controversy. It is therefore an open question whether the Perceptual Analogy-insofar as it aims at the elucidation of various platitudes about emotion-can be adequately defended against the various criticisms that have been leveled against it. Let me concede, however, that the three strategies just introduced-although maybe somewhat costly-might be adequate to meet the objections ${ }^{34}$ on the condition that there is no alternative way to think about emotions which not only fares at least equally well as the Perceptual Analogy in accounting for core aspects of emotions, but also may provide an adequate account of those aspects which cause trouble to the perceptualist.

I will argue that such an alternative is possible. The project I am after, indeed, is to defend the development of another systematic way of thinking about emotions. With the perceptualist, I agree that modelling emotions on a better understood kind of thing is a powerful way to come to grips with them. I disagree however that to do so, we should adopt the Perceptual Analogy. As I will argue in the next section,

\footnotetext{
31 For a similar point, see Brady (2010).

32 Arguably, the following moves are all made in some form or other in Tappolet (2016).

33 See, for instance, Furtak (2018) and Mun (2019) for the claim that emotions are perception-like in being vehicles of knowledge and rational.

34 If the advantages of the view are significant enough, indeed, we may be justified in accepting a potentially revisionary account of emotion and/or perception (if, for instance, we adopt a more 'liberal' conception of the latter; Tappolet 2016).
} 
there is an alternative analogy-one between emotions and some actions-which may on the whole be better than the Perceptual Analogy in virtue of capturing the platitudes about emotions that the Perceptual Analogy initially appeared to capture and elucidating further platitudes about emotions better than the Perceptual Analogy. At the very least, a non-perceptualist account of most of emotion's RU features should put some pressure on us to understand the other features in non-perceptualist terms as well.

\section{Introducing the Action Analogy}

\subsection{Preliminaries}

Recall the RU features of emotion we started with: (1) intentionality, (2) phenomenology, (3) passivity, (4) conflict with belief, (5) appropriateness. As suggested in the previous section, (4) plausibly should be replaced with (4*) rational conflict with belief: emotions can enter in rational conflict with belief (unlike ordinary perception). And (5) should be replaced with ( $\left.5^{*}\right)$ appropriateness as merit: emotions can be appropriate or inappropriate in the sense of being merited or not merited. To these, we should add some other features we mentioned in 3.1: (6) cognitive dependence: emotions have cognitive bases - mental states which provide their intentional object; (7) reasons \& reasons-responsiveness: emotion can be supported by normative reasons, and one can feel an emotion for a reason.

This is a large list of platitudes about emotions. But I think that a certain analogy can ultimately elucidate and account for them in a systematic way. I think that emotion shares many of these features with action, where by 'action' I mean (roughly) the actions we would intuitively see as bodily, in contrast with what we would call 'mental' actions. ${ }^{35}$ So I claim that there is an interesting and theoretically fruitful analogy to be drawn between emotion and things like helping, hugging, kissing, and the like. ${ }^{36}$

Before going into the details of the analogy, let me briefly discuss two worries about the analogy one might have from the outset, independently of any particular way it might be pursued. Addressing them will help clarify the project I am after. First, one might think that the analogy is simply a non-starter. Clearly, one might say, something we can be certain about is that emotions are not actions. For one thing, one of our platitudes says that emotions are passive; this surely rules them out as candidate actions. I think however that this complaint should be rejected, at least

\footnotetext{
35 There is a dialectical reason for framing the analogy as between emotions and bodily actions as opposed to mental actions (which might include judgments, as admitted later in the text). It's that it forces us to stay neutral on certain claims about emotions which are customarily accepted in the literature-such that emotions are representational states (rather than merely presuppose them) or that they are epistemically special. Given that we are not tempted to say such things about helping, hugging, and the like, the Action Analogy forces us to resist accepting these claims unless we need to.

36 As will become clear shortly, and as the examples suggest, the analogy in question is between emotion and a certain class of actions rather than actions in general.
} 
at this stage. First off, depending on what the best account of action turns out to be, emotions might in fact be actions. Jean-Paul Sartre, for one, may be interpreted as making precisely this claim when he argues that an emotion is "an organized system of means aiming at an end" (Sartre and Frechtman 1948, 32; quoted in Scarantino 2016,22 ). Moreover, if a judgment turns out to be a species of action, then the socalled cognitive theory of emotion can be interpreted as a view identifying emotion with a certain kind of action. Robert Solomon, a committed cognitive theorist, goes so far as claiming that, just like we choose our actions, we choose our emotions, in turn rejecting emotion's alleged passivity (Solomon 1973). More generally, emotion theorists from various fields, including psychology, appear to take the identification of emotion with action quite seriously (e.g., Moors and Boddez 2017). ${ }^{37}$ Even if, as theorists sympathetic to the claim that emotions are actions may ultimately admit, emotions are not strictly speaking actions, however, the complaint under discussion fails to appreciate the project we are engaged in here, which is not a reductive project, or at least need not be. Just like the perceptualist is not necessarily, and not generally, in the business of arguing that an emotion is a form of perception like any other, the advocate of the Action Analogy need not be in the business of arguing that emotions are actions. Let me then explicitly say that everything I say in this paper should be compatible with the claim that emotions are not actions. ${ }^{38}$ Still, emotions may be like actions in some interesting respects, and-borrowing a page from the perceptualist's book - an account of emotion's core features modelled on an account of similar features in the action case may be successful.

Now, one might concede that the Action Analogy might be a theoretically fruitful way of thinking about emotions, but might then insist that this is because of the seemingly obvious fact—emphasized by many theorists (e.g., Deonna and Teroni 2012) - that emotions entertain an intimate relationship with action. According to what Scarantano calls the 'motivational tradition' in emotion theory (Scarantino 2016), which goes back to Aristotle, an emotion is a distinctive kind of motivational state. On a popular version of this general view, championed by Nico Frijda (Frijda $1986,2007),{ }^{39}$ an emotion is a certain kind of action tendency or 'readiness' to act.

\footnotetext{
37 See also so-called 'enactivist' approaches to emotion (e.g., Colombetti 2014). Although the framework defended in the text might have some affinity with such approaches (e.g., in denying that emotions are independent ways of representing aspects of the world), the connection between such approaches and the Action Analogy is far from straightforward. For one thing, the Action Analogy may be paired with traditional, non-enactivist approaches to the mind. At bottom, the analogy enjoins us to pursue a parallel study of both emotion and action, and in particular to look at how insights from action theory may be extended to the theory of emotion. At this stage, it is neutral on what these insights might be.

38 To be sure, one might want to consider the possibility of adopting a liberal conception of action whose consequence is that an emotion is an action, inspired by a similar move made by the perceptualist (2.3). This potentially revisionary possibility, I take it, should not be pursued at this stage of the dialectic.

39 See Deonna and Teroni (2012) for a proposal along similar lines with a view to developing a positive conception of the epistemological significance of emotions. As far as I can tell, these authors might find the Action Analogy congenial to their project, although — as emphasized shortly — there is, prior to inquiry, no obvious way to go directly from that analogy to any particular theory of emotion.
} 
In experiencing fear, for instance, one is poised to act in various ways appropriate to the situation. An emotion might therefore be a conative state constitutively linked to various kinds of action, which might explain why the Action Analogy may initially seem attractive. If this is right, this might raise the suspicion that the Action Analogy either lacks originality_-given that some motivational theories may be interpreted as relying on an analogy of this sort ${ }^{40}$ - or else is unmotivated and unnecessary (and potentially misleading) — as it appears that if an emotion is a conative state of sorts, then an adequate analogy, if pursued at all, should not be between emotion and action but between emotion and ordinary conative states such as desires.

Let me briefly say why I don't think my project faces this dilemma. First, it may be true that something like the Action Analogy is implicit in various defenses of the motivational theory. ${ }^{41}$ But it is one thing to implicitly rely on a certain strategy, quite another to spell it out in an explicit form. And the current discussion is aimed at doing precisely that. To the extent that the Action Analogy is explicitly relied on in the contemporary literature, furthermore, it is not in the detailed and systematic way that the Perceptual Analogy has been deployed by several theorists. As far as I can tell, indeed, by contrast with the Perceptual Analogy, no sustained and detailed defense of the Action Analogy itself has ever been proposed. The charge that the Action Analogy is unmotivated and unnecessary can also be rebutted by explicitly saying that the immediate theoretical agenda of this paper is not to argue for a specific theory of emotion, not even for one of the theories-the motivational theory and the 'agential' theory-with which it might appear to have the most affinity. To be sure, the Action Analogy may be deployed in support of the motivational theory (say), but as far as I can tell, it might lead to a view of emotion quite different from it. ${ }^{42}$ Since the denial of the motivational theory is compatible with the Action Analogy, my project is at this stage neutral on that specific view. Of course, the Action Analogy is fruitless if no genuine account of emotions is ultimately provided, that is, if it rests content with merely noting points of similarity, ${ }^{43}$ but if the argument in the text is on the right track, then there is no reason to suppose that such an account is not forthcoming. The primary aim of a philosophical theory of emotion, as I see it, is to elucidate and systematize various platitudes about emotions, that is, to account for the various aspects our most stable intuitions attribute to emotions and how such aspects relate to one another. ${ }^{44}$ This goal, I take it, can be pursued without having a

\footnotetext{
${ }^{40}$ A similar complaint could be raised in light of the fact, admitted in the previous paragraph, that some emotion theorists have already defended the view that emotions are actions.

41 And of course, it may be implicit in various defenses of the view that emotions are actions.

42 My own conviction is that it will. The slogan from the beginning according to which emotions are the internal counterparts of bodily movement is helpful in bringing out the idea that, just as bodily actions have significance apart from their consequences, emotions have significance apart from the things they might motivate us to do.

43 Adapting a distinction I introduced in Ft. 8, the latter would constitute a modest way of pursuing the Action Analogy.

44 This is not to say that no revisionary account of emotions could ever be properly defended. All I mean here is that, unless (perhaps until) we have independent reasons to deny any of the relevant claims, a nonrevisionary account is preferable to a revisionary one.
} 
preferred theory from the outset. In fact, if the methodology proposed here is at all promising, we should be open-minded about the outcome of our inquiry. I conclude that, rather than worrying that the Action Analogy might be unmotivated (or unnecessary), we should wait and see how far it can go in giving us what we want from a theory of emotion and, ultimately, what the resulting picture might look like. ${ }^{45}$

\subsection{The Action Analogy Captures the Differences Between Emotion and Perception}

Let us now turn to the Action Analogy. An immediate question raises itself: what is an action? This is a very difficult question, but at this stage I can help myself (like the perceptualist often does in their case) with a broadly intuitive account, leaving the development of various versions of the Action Analogy for future work. A traditional way to start is by asking what the difference is between an action and a mere bodily movement. In a way, an action involves bodily movement plus something else. At the very least, an action is a bodily movement suitably related to the agent's mental states - chiefly their beliefs, desires, and intentions. It is, the thought goes, in part in virtue of being related in a certain way to these states that a bodily movement is an action rather than a mere physical happening. Notice that this structure appears to be shared by emotion. An emotion involves a physiological arousal of sorts, but it is not a mere physiological arousal. ${ }^{46}$ Perhaps, then, what turns a physiological arousal into an emotion is in part the fact that it is connected to further mental states in some way. ${ }^{47}$ Bodily changes are to emotion what bodily movement is to action.

With this way of framing the basic question about the nature of emotion, it should be evident that there is no reason to be suspicious of the possibility of modelling the dependence of emotions on further mental states on the dependence of actions on further mental states. Indeed, we seem to have in both cases a state or occurrence that

\footnotetext{
45 That said, I do think that the slogan formulated at the beginning of this paper-that emotion is the inward counterparts of bodily movement-is a particularly helpful way to express the sort of view the Action Analogy most naturally leads to which, as far as I can tell, has not received any sustained defense in the literature. The only place I know of which comes close to defending a view like this is Jennifer Church's paper (in French) "L'émotion et l'intériorisation des actions" (1995). Her view is that emotions are actions that have been internalized. It should be clear however that this is not the only way we might precisify the slogan.

46 To anticipate the objection that emotions need not involve physiological changes, we may instead decide to attend to some sort of core affective state or occurrence which in principle could exist without the associated emotion (e.g., a feeling) and ask what might turn it into a full-blown emotion.

47 As we have seen, no such dependence with prior mental states appears to be required for having a perceptual experience. It appears, therefore, that the Action Analogy may be better suited to capture the phenomenon of cognitive dependence than the Perceptual Analogy. That said, I don't think that the perceptualist is without resources to accommodate cognitive dependence (see Ft. 21), so I do not wish to insist too much on this point here. For I think it is only when we have arrived at an adequate understanding of some other aspects of emotions (in particular their intentionality and normativity) that a particular account of cognitive dependence at odds with perceptualism will emerge.
} 
is caused by, and owes part of its identity to, things outside it, namely further mental states of the agent. I take it then that the Action Analogy has ample resources to account for cognitive dependence (6) in a straightforward way: namely on the model of the dependence of bodily movement on states like intention, belief, and desire. ${ }^{48}$

A further point of analogy between emotion and action is that they can both be justified by normative reasons, and can be had/done for a reason ((7) reasons \& reasons-responsiveness). In fact, both emotion and action may be supported by the same reasons, reasons on which one can then base one's emotion and action. Suppose Martin did something wrong, and that this justifies both punishment (e.g., saying something hurtful) and anger. Having registered the significance of Martin's act, John thereby reacts in two ways: he is angry with John and he punishes John. Both reactions, furthermore, are made in response to what John has done-John both punishes and is angry with Martin for the thing he has done. This parallel is striking and gives us a reason to take seriously the idea that (1) normative reasons for emotion are ultimately of the same kind as normative reasons for action and (2) it is possible to model the reasons-responsiveness at play in emotion cases on that at play in action cases. At any rate, action theory and the philosophy of normativity are replete with accounts of reasons-responsiveness that might apply to emotions. ${ }^{49}$ Given the phenomenon of cognitive dependence, it is in fact quite plausible that reasons-responsiveness in the emotion and action cases will in part have to do with their relationship to prior mental states of the agent, these states furnishing the basis in light of which one responds in emotion or action.

We are now in a position to say that the Action Analogy has a clear advantage over the Perceptual Analogy in that it has the resources to capture two features we have seen the latter has trouble with: (6) cognitive dependence and (7) reasons \& reasons-responsiveness.

\subsection{The Action Analogy Better Captures Conflict with Belief and Appropriateness}

At this stage, the perceptualist might insist that insofar as these aspects are independent of those aspects that grounded their epistemic claim $((1)-(5))$, the fact that their analogy is not the best to capture them is not a problem to their view. As argued in Sect. 3.2, however, two of the features the perceptualist thinks emotion and perception share-when properly elucidated - turn out to constitute a point of difference between them. Emotion is not just-like perception-something that can

\footnotetext{
48 Relevant discussions from action theory are countless, but see, e.g., Bratman (1987), Davidson (1971), Enç (2003), and Mele (1992). Notice that, just as it is common in action theory to posit cognitive and conative attitudes as the causal determinants of action, it is common in the philosophy of emotion to posit cognitive and motivational 'bases' (Deonna and Teroni 2012; Tappolet 2016). This gives some support to the claim that action and emotion share some structural similarities.

49 For a recent general account of reasons-responsiveness, see Lord (2018). To be sure, emotions might be so different from action in further respects that any notion of reasons-responsiveness we can apply to them won't be the same as the one that applies to action. As I will suggest in 3.4, a case however can be made for the claim that emotions are analogous to a certain class of actions, namely those that exemplify some level of spontaneity.
} 
conflict with belief; it is something-unlike perception-that can enter in rational conflict with belief. And it is not just something-like perception-that can go right or wrong, or be appropriate or inappropriate, in some loose sense; it is somethingunlike perception-that can be appropriate or inappropriate in the sense of being merited or not merited. ${ }^{50}$ Or so I have argued. In this section, I briefly explain why an account of rational conflict with belief $\left(4^{*}\right)$ and appropriateness as merit $\left(5^{*}\right)$ in the emotion case may straightforwardly be modelled on an account of these features in the action case. I will then suggest, in the next section, that the fact that actions and emotions share so many RU features should put some pressure on us to understand the remaining RU features of emotions-chiefly intentionality, phenomenology, and passivity - in non-perceptualist terms. Although nothing like a knock-down argument against perceptual accounts of such features will be given, the fact that there is a plausible non-perceptual story of emotion's core aspects should at least make us at least skeptical of the success of the perceptualist's project. ${ }^{51}$

First off, notice that an interesting analogy to draw between emotion and action is that both can not only conflict with belief but also count as (or, rather, make their bearer) irrational for that reason. Consider the case of the dieter who judges that he should not eat another piece of cake but nonetheless eats it anyway. In such a case, it seems quite sensible to call his action irrational in light of the fact that it conflicts with his better judgment. Similarly, when one feels afraid of a height while judging that one is safe, it seems sensible to call the fear one feels irrational in light of the fact that it conflicts with one's judgment. So, there is a clear analogy to be drawn between recalcitrant emotions and akratic actions. At any rate, the Action Analogy at least accommodates the fact that an emotion in conflict with a judgment can be irrational, something the Perceptual Analogy has trouble doing.

As should be clear by now, however, pointing to an apparent similarity between emotion and action is not the same thing as showing that this similarity is real- that, for instance, the sense in which an emotion can be in rational conflict with judgment is the same as the sense in which an action can be in a rational conflict with judgment. Indeed, it might be the case that the best account of the irrationality of akratic action cannot plausibly be extended to the case of emotion. All the same, there are reasons to think that this conclusion is a bit premature. It seems to be a desideratum that an adequate account of recalcitrant emotions should avoid two horns of a certain dilemma (Benbaji 2013, 580). On the one hand, the account should avoid having to attribute a contradiction to the agent, as a view claiming that an emotion is an evaluative judgment (whose content is in conflict with another judgment in cases of recalcitrant emotions) would presumably have to. The reason is that the sort

\footnotetext{
50 For a forceful argument against understanding appropriateness/fittingness/merit under representational lines, see Svavarsdóttir (2014). It might be worth noting that a representationalist conception of appropriateness constitutes a minority position in the philosophy of normativity. In that literature, the notion is generally understood normatively. For discussion, see Howard (2018).

51 Like expressivism in metaethics, perceptualism in the philosophy of emotion should be seen as a research program whereby we investigate how far we can defend a certain picture. I have myself defended the perceptualist view against objections in a couple of places (Naar 2016; Milona and Naar 2020). Needless to say, this is compatible with finding an alternative picture initially more attractive.
} 
of irrationality involved in holding two contradictory judgments at the same time seems too radical—or at any rate intuitively of the wrong sort-to adequately capture the sort of irrationality involved in cases of recalcitrant emotions. On the other hand, the account should avoid ending up denying that emotions cannot be deemed irrational after all, a claim which would clearly conflict with a fairly robust platitude about emotions. As we have seen, this is a reason why one might be dissatisfied with the perceptualist's account of recalcitrant emotions as analogous to perceptual illusions.

I think that an analogy between recalcitrant emotions and akratic actions is the most promising way to avoid both horns of the dilemma (Benbaji 2013). To be sure, there are some conceptions of akratic actions which ascribe contradictory judgments to the akratic agent, and some which even deny that akratic actions are irrational. Such accounts, however, are problematic for the same reasons the views of emotions which do not avoid the above dilemma are. As a result, the literature on akratic action is replete with proposals attempting to find a middle ground between ascribing the akratic agent contradictory beliefs and denying the irrationality of akratic action. This is not the place to discuss these proposals, and whether they might be extended to recalcitrant emotions; my point is simply that this should give us hope that a superior account of recalcitrant emotions can be properly defended via the deployment of the Action Analogy. ${ }^{52}$

Now, recall the notion of intrinsic correctness conditions. Roughly, these are conditions which make a certain response fitting in a way that is tied to its nature. We have seen moreover that a natural way of construing the notion of appropriateness is in terms of merit. Since perception is not merited in any obvious sense, we concluded that the sense in which emotions can be appropriate or inappropriate is not the same as the sense (if any) perception can be appropriate or inappropriate. ${ }^{53}$

I think that appropriateness as merit can be captured just as straightforwardly by the Action Analogy. To see that the Action Analogy has the necessary resources, we simply need to reflect on the question whether actions can have intrinsic correctness conditions as well. If they can, then we can be hopeful that whatever account best captures them in the action case will extend to the emotion case. And some action types do seem to have intrinsic correctness conditions. There are appropriateness conditions which seem to apply to certain action types in virtue of the kind of thing they are. Take punishment. An instance of punishment is appropriate or fitting in the relevant sense only if the target of the punishment is punishable. ${ }^{54}$ When we say that

\footnotetext{
52 For a particularly attractive extension of Davidson's account of akratic action to recalcitrant emotions, see Benbaji (2013). I should also note that Benbaji explicitly draws an analogy between emotion and action in her paper, albeit for a more specific purpose.

53 To put my cards on the table, I think that the notion of appropriateness that perceptualists are happy to apply to perception is merely stipulative, having no real grounding in commonsense thinking. My suspicion is that they take 'appropriateness' and 'correctness' to be synonymous, and since 'correctness' may more easily admit a non-normative, representational interpretation, perceptualists are happy to interpret 'appropriateness' non-normatively.

54 Of course, this might not seem to be very informative, but it is no less informative than saying that admiration is fitting when its object is admirable.
} 
someone is punishable, we say that they deserve or merit punishment for what they did. And this is different from saying that it would be correct to punish them because failing to do so would have bad overall consequences-i.e., an extrinsic condition.

What is meant by merit here? As I argued elsewhere (Naar 2017), merit is constitutively related to a class of normative reasons that are tied to the nature of the response they favor. ${ }^{55}$ Merit-based reasons for admiration, for instance, are those having to do with some good aspect of the object of one's emotion. Given this picture, we can see that merit-based reasons are clearly at play in the action case as well. Merit-based reasons for helping will have to do with facts about need, whereas merit-based reasons for punishing will have to do the wrongness of an action one has performed. If this is on the right track, and given the parallel with action, it turns out that this account of the sense in which emotions can be appropriate (the sense of being merited) might shed light on the connection between emotions and reasons (i.e., (7)). ${ }^{56}$

\subsection{How About Intentionality, Phenomenology, And Passivity?}

Suppose that the Action Analogy is better than the Perceptual Analogy at capturing the sense in which emotions can conflict with belief and the sense in which they can be appropriate or fitting. It follows from this that any remaining basis for their epistemic claim the perceptualist may enjoy will be too thin to be acceptable. Indeed, the mere fact that emotion and perception both have intentionality, a phenomenal character, and passivity does not seem enough, without further argument, to ground such a strong theoretical claim as that emotion is epistemically special the way perception is. As a result, the perceptualist cannot rest content with these points of similarity, and must thus supply an independent argument for their epistemic claim. Still, the perceptualist might be hopeful that the best account of the intentionality, phenomenology, and passivity of emotion can be derived from an account of these features in the perceptual case.

That said, it is important to stress that we should not look at emotion's core features as independent units to be explained separately. Indeed, it is highly plausible that the various aspects of emotion are to be elucidated in inter-related ways. As we have seen, reasons-responsiveness and cognitive dependence are plausibly related by the fact that it is in part in virtue of their being based on certain cognitive states

\footnotetext{
55 Views that tie fittingness/appropriateness/merit to normative reasons, although in different ways, are in fact standard in the philosophy of normativity. For an overview, see Howard (2018).

56 The account of merit sketched here should dispel the worry that what I take to be intrinsic correctness conditions on action might in fact be conditions on intention. Given that it is very plausible that there are normative reasons, including merit-based normative reasons, for action, the parallel between the intrinsic correctness conditions of emotion and that of action holds if such conditions are ultimately a matter of normative reasons. Another concern one might have is that it is possible to hold that merit is at bottom a representational matter - that, e.g., meriting punishment is to be justifiably judged to have the property of punishability. Besides sounding circular, this account should appear much less natural, and less wellmotivated, than one that simply claims that to merit punishment is to have certain properties that provide certain reasons for punishment. Thanks to a reviewer for discussion.
} 
that emotions might be said to be responses to reasons (reasons which are arguably represented by the relevant states). Given this, it seems plausible that, if appropriateness is not to be understood along representational lines but normatively, an emotion is appropriate just in case it is formed in response to the reasons there are in its favor. ${ }^{57}$ Notice now that since there is no notion of representational adequacy (correspondence, adequacy, truth, etc.) that applies to emotion in any obvious way, it is unclear what positive reason we might have for understanding emotion's other features — chiefly its intentionality - under perceptual or representational lines. Worse still, it is unclear what reason there might be for thinking, not only that emotions involve some kind of representation (which might well be the case, given some representational view of phenomenology, say), but that the kind of representation they involve is evaluative. If evaluative properties are then hypothesized to be themselves the reasons for emotion-a not so implausible claim (e.g., Peter's anger is appropriate because Mary's remark was offensive) — it becomes very hard to maintain the claim that emotions are representations of such properties if that claim would not be justified in the action case. ${ }^{58}$ Just as the fact that Peter's avoiding Mary is appropriate because her remark was offensive does not imply that Peter's avoidance behavior itself represents-let alone is a perceptual experience as of-Mary's remark as offensive, the fact that Peter's being angry with her is appropriate because her remark was offensive does not imply that his anger itself represents her remark as offensive. If the offensiveness of Mary's remark is to be represented by Peter, it will presumably have to be represented by some further state of his. ${ }^{59}$

Now, one might object that since it is unclear how the Action Analogy can accommodate the intentionality of emotions (and other seemingly recalcitrant RU features), we should not give up on the Perceptual Analogy just yet, at least insofar as it at least provides an account of it. Note though that regardless of whether the Action Analogy has the resources to capture the intentionality of emotion, the following point still holds: there is no positive reason for accepting the perceptualist's epistemic hypothesis if features such as cognitive dependence, reasons-responsiveness, and appropriateness are adequately explained under non-perceptualist lines. So even if we must maintain that emotions are representational, we are not rationally compelled to accept the much stronger claim that emotions are (non-conceptual) perceptual experiences of evaluative properties. ${ }^{60}$ In the following, however, I give

\footnotetext{
57 An alternative claim would be that an emotion is appropriate just in case there are sufficient reasons in its favor, reasons which might constitute the basis on which one forms one's emotion.

58 Things are not clearly better for the perceptualist if we accept the so-called fitting attitude analysis of value, on which evaluative properties are grounded in reasons for certain responses. For an overview, see Jacobson (2011).

59 I am not sure emotions entail a representation of value by the agent, rather than (say) the natural properties underlying the relevant evaluative property (Deonna and Teroni 2012). But if they did, we have good reasons for thinking that the relevant representation would be distinct from emotions, given that the epistemic access to reasons for a certain kind of response $\mathrm{R}$ are generally provided by responses other than R (Müller 2017).

60 As noted earlier, the argument in the text is not meant to cast doubt on direct arguments to the effect that emotion and perception have a similar epistemic profile. It is not clear how such arguments could ultimately work, however, in the absence of a more general analogy between emotion and perception.
} 
some reasons for thinking that the Action Analogy has the resources to capture the intentionality, phenomenology, and passivity of emotion in a satisfactory way. ${ }^{61}$ This will help us zero in on the kind of action that emotions might, down the line, be most analogous to.

Facing the Action Analogy, one might retort that, at first sight, we wouldn't say that actions are intentional in the sense that emotions and perceptions are intentional-actions are not about anything. This, however, may be too quick, as there are grammatical constructions which suggest that at least some action types are intentional in the relevant sense. Consider the following sentence:

\section{John punishes Martin.}

(1) is similar to the following sentence in involving an expression taking an object:

\section{John is angry with Martin.}

In a sense, John's punishment is 'about' Martin a similar way John's anger is about him. We may therefore have the seeds to capture the intentionality of emotions. ${ }^{62}$ But do we really have genuine intentionality in the action case? This is a difficult question which cannot be fully answered here. For my purposes, I will merely note that there are conceptions of intentionality which would allow certain action types to instantiate genuine aboutness. Following Chisholm (1957), for instance, we might think that a mark of intentionality is the intensionality of the linguistic constructions we might use to talk about the relevant phenomena. To be sure, actions can be described as purely physical phenomena, which implies that the relevant linguistic constructions will be extensional. For instance, there is an extensional reading of John punishes Martin which (1) implies that Martin exists and (2) passes the test of the substitutability of co-referential terms (here, 'Martin') salva veritate. According to Chisholm's criteria, then, the action type punishing would not count as an intentional phenomenon.

Admittedly, there might be a use of 'punishing' which is extensional. This, however, does not imply that it cannot also occur in an intensional context. In fact, the eminently plausible claim that actions are not mere bodily movements-hence not mere physical happenings_-gives us a reason to think that true reports of their occurrence will be intensional in many contexts. In reporting an action performed by an agent, we typically aim to capture the perspective they have on their situation,

\footnotetext{
61 Of course, the perceptualist is free-and likely - to find the following sketch unsatisfactory. For I will not give a positive argument for the claim that emotion's intentionality is not perceptual intentionality. This would be too big a task for a single paper. The aim is more modest. It is to show that, absent some positive reason for thinking that emotional intentionality is perceptual, what we need is $a$ way to accommodate the intentionality of emotion that does not seem to violate some platitudes about it. Thanks to a reviewer for discussion.

62 It is important to remind ourselves here that we do not equate intentionality with representation. Intentionality is aboutness, while representation arguably is not just aboutness.
} 
including the perspective they have on the 'object' of their action. In punishing Martin, John represents Martin a certain way and not in other ways such that, if we are to really capture the fact that John punishes Martin, we should understand the relevant sentence (John punishes Martin) intensionally.

Notice that this point is compatible with a claim, put forward by Crane (2009) among others, that every intentional entity-every entity which exemplifies aboutness - requires a representation (Crane 2009). Granted, many intentional states are tied to representation in virtue of being themselves representational. This, however, need not be the case. It may be the case, indeed, that some intentional entities are tied to representations by being based on them ((6) cognitive dependence). The idea of an action that instantiates aboutness, therefore, does not conflict with the idea that aboutness requires representation; after all, in order to act on behalf of some particular person (say), it may be required that one represent that person under a certain aspect. $^{63}$

In any case, the fact that there are actions-call them object-directed actionswhich look like they have intentionality in a fairly strong sense gives us at least some hope that an analogy between emotions and these actions can adequately capture the intentionality of emotions. Now, an implication which makes the Action Analogy different from the Perceptual Analogy is that we may not need to identify emotions with a certain kind of representational state to capture their intentionality, just as we do not need to-neither should we-identify object-directed actions with representational states in order to do so. ${ }^{64}$ Neither does the Action Analogy imply that emotions will have a sort of content that makes them suited to play the significant epistemological role played by perception. Given that object-directed actions are not generally apt to provide justification for beliefs about their object's value, pursuing the Action Analogy should make any claim about the epistemic specialness of emotion look suspicious. ${ }^{65}$

As for the phenomenology of emotion, I think that the Action Analogy can capture it to some extent in the following way: just like there is a phenomenology of bodily movement, there is a phenomenology of the physiological changes involved in emotion. The question then is whether the phenomenology of physiological changes is all there is to the phenomenology of emotion, and whether whatever phenomenology we should add to it has its counterpart in the action case. And there is some evidence which support, albeit inconclusively, a similar way to account for the phenomenology of emotion, on the one hand, and the phenomenology of (objectdirected) action, on the other. First, note that, by contrast with many ordinary

\footnotetext{
63 Perhaps this is enough to support the attribution of a content to action. As long as this does not mislead us into thinking that action itself furnishes the relevant representation, I do not have any objection to this decision.

64 Of course, this is compatible with accepting that emotions and actions presuppose certain representational states (including the immediate states on which they are thought to depend). I take it that the debate is not about this weaker, less controversial claim.

65 The Action Analogy is compatible with the claim that emotions do play a more modest epistemic role. It may turn out, for instance, that emotions come with certain dispositions to attend to certain aspects of the environment (Brady 2013).
} 
perceptual experiences, emotions' phenomenology lacks the sort of transparency often appealed to by representationalists about consciousness (e.g., Harman 1990). If one is asked to focus on the way one's emotion feels, one is indeed likely to turn one's attention inward, so to speak, and focus on what one's body feels like. ${ }^{66}$ And this may be what happens, at least in part, if one is asked to focus on what's it's like to act. Second, limited empirical evidence suggests that certain emotion types may share the same phenomenology. It may be the case, indeed, that anger and fear share - at least sometimes - the same bodily profile (e.g., Cannon 1929; Schachter and Singer 1962). Although certainly controversial, suppose this hypothesis turns out to be true. It would follow that a mere appeal to phenomenology-which presumably would be a natural way to go in the context of a deployment of the Perceptual Analogy ${ }^{67}$ - would not help the perceptualist to distinguish between clearly distinct types of emotions. ${ }^{68}$ So, if this hypothesis is right, it might turn out that the perceptualist is unable to claim that her account of emotional phenomenology is better than any account we might devise on the basis of the Action Analogy. Furthermore, I think that the Action Analogy would in fact be better suited to account for emotional phenomenology if the relevant hypothesis happened to be true. For it is quite plausible that two distinct action types (or at least some tokens of two distinct action types) may share the same bodily profile. Perhaps, indeed, we can imagine two actions with the same bodily phenomenology, but one is an instance of punishment while the other is an instance of abuse, depending on the agent's further mental states and some further facts about their situation. ${ }^{69}$ If this is on the right track, then I don't see why an account of emotional phenomenology could not be modelled on an account of the phenomenology of agency. ${ }^{70}$

One might retort, however, that there is a clear phenomenological difference between emotion and action which has to do with their relation to agency. By contrast with action, emotions are experienced as passive, things we undergo rather than things we actively do and over which we have direct control. This seems to be a clear disanalogy between emotion and action. And I agree that an account that makes emotion something completely under our control would conflict with a

\footnotetext{
66 This is most striking in cases in which one does not quite know what the object of one's emotion is, as when one is angry but does not quite know why. It should be clear that one would not find any difficulty in attending to how one's emotion feels in a case like this.

67 At least for a representationalist about phenomenology.

68 Of course, the perceptualist is free to develop an account of the phenomenology of different emotion types as having distinctive marks, but establishing it would require substantive discussion. Generally, however, it is not clear that a detailed, non-question-begging phenomenological description of emotion types could be given. And even if it could, the resulting account may be compatible with ways to develop the Action Analogy that rely on less minimal accounts of the phenomenology of agency. Thanks to a reviewer for discussion.

69 Thanks to William Melanson for suggesting this example.

70 To be sure, a large part of the phenomenology of action derives from the phenomenology of all the mental states one is in while performing it, such as what one sees at the time of action. The strategy in the text, however, is to isolate a dimension of the phenomenology of action which does not derive from the phenomenology of these further states and to compare it with a dimension of the phenomenology of emotional episodes which does not derive from the phenomenology of its cognitive bases (among other things one might be experiencing at the relevant time).
} 
deeply entrenched platitude about it, which is why an account that makes emotion passive in some sense might be preferable, at least initially (i.e., until further reasons are given to reject the alleged platitude). The question however is, in what sense are emotions passive? And is the sense in which emotions are passive the same as the sense in which perceptual experiences are passive, as the perceptualist suggests? Although this is not the place to provide a full defense of this claim, there is some reason for thinking that emotional passivity is not quite the same as the passivity of perception. Consider a perceptual experience as of a color. It seems that, in experiencing the color, you are the recipient of something that is completely given to you, so to speak. You don't have a 'say' in what is happening to you; you see the color whether you like it or not, a bit like a piece of canvas receives the paint that is thrown at it. Rather than receiving something from the outside, by contrast, in feeling joy at the view of the color you respond to it in a certain way; "it is you who 'speaks"' (Müller 2018). In a way, then, in experiencing an emotion, you do something, namely bring some aspect of yourself to bear on the situation, something that the canvas is unable to do. ${ }^{71}$ Although this thought needs to be fleshed out, it suggests that a view of emotional passivity should not be such as to deny the responsive character of emotions. Notice now that, once this further aspect of emotions is accepted, the Action Analogy emerges as particularly suitable to account for it. For one thing, actions are responses in some fairly obvious sense. It is the case, moreover, that certain action types (or action tokens of certain types) do not instantiate the complete control that intentionally raising one's arm enjoys. In fact, a cursory look at the wide range of possible actions should reveal that control over what we do is often not of that straightforward sort. Notably, some actions display a level of spontaneity that things such as helping, hugging, and punishment (e.g., slapping) can clearly instantiate. ${ }^{72}$ I contend, then, that an analogy between emotions and (objectdirected) spontaneous actions is a promising way to come to grips with the aspects that make emotions appear so distinctive.

\section{Conclusion}

The Perceptual Analogy has been working a bit as a research program in recent years - that of looking into the philosophy of perception to inform the debate over the nature of emotion. In doing so, perceptualists have provided a coherent,

\footnotetext{
71 Jean Moritz Müller (2018) discusses the responsive character of emotions in the context of defending a particular account of their intentionality rather than their passivity. But if the Action Analogy is on the right track, I think that the picture that will emerge is one in which the features we commonly attribute to emotions will be elucidated in a way that reveals their relationship to each other, which is exactly what an adequate account of emotions should do.

72 Perhaps, then, (3) passivity should be replaced with $\left(3^{*}\right)$ passivity as spontaneity: emotions are passive in the sense that they are responses which exhibit spontaneity, and in that respect are analogous to certain actions. This is not the place to provide a full defense of this interpretation of the passivity of emotion, but given the other features of emotion (notably reasons-responsiveness), it wouldn't be surprising if this was the right one. Thanks to Neil Roughley for the suggestion that emotions are analogous to spontaneous actions. On the spontaneity of emotion, see Müller (ms.).
} 
systematic, and philosophically interesting account of emotion's various aspects. In this paper, I have argued that another analogy-the Action Analogy-can be deployed to provide an alternative account of emotion, and one that is at least just as coherent, systematic, and philosophically interesting as the one that is based on the Perceptual Analogy. Importantly, the Action Analogy, suitably developed, might lead to a picture of the significance of emotion that is radically at odds with the perceptualist's, as it does not attribute to emotion any special epistemic status. Of course, this paper has only been only exploratory - all the substantive work is still to be done. But the striking parallels between emotions and certain actions should at least give us some reason for thinking that the philosophical significance of emotions lies elsewhere.

Acknowledgements I am grateful to Paul Boswell, Moritz Bütefür, Jerry Cederblom, Jason D'Cruz, Julien Deonna, Laura Grams, Franziska Hesse, Alex Hyun, Flavia Felletti, Stefan Mandl, William Melanson, Michael Milona, Moritz Müller, Andrew Newman, Michele Palmira, Robert Roberts, Mauro Rossi, Neil Roughley, Astrid Schomäcker, Neil Sinhababu, Christine Tappolet, Fabrice Teroni, André Waldheuser, two anonymous referees, and audiences at the University of Montreal, the University of Nebraska-Omaha, and the University of Duisburg-Essen. This paper is part of the project "The Agency in Emotion" (project number: 422216360), generously supported by the German Research Foundation (DFG).

Funding Open Access funding enabled and organized by Projekt DEAL.

Open Access This article is licensed under a Creative Commons Attribution 4.0 International License, which permits use, sharing, adaptation, distribution and reproduction in any medium or format, as long as you give appropriate credit to the original author(s) and the source, provide a link to the Creative Commons licence, and indicate if changes were made. The images or other third party material in this article are included in the article's Creative Commons licence, unless indicated otherwise in a credit line to the material. If material is not included in the article's Creative Commons licence and your intended use is not permitted by statutory regulation or exceeds the permitted use, you will need to obtain permission directly from the copyright holder. To view a copy of this licence, visit http://creativecommons.org/licen ses/by/4.0/.

\section{References}

Benbaji, H. (2013). How is recalcitrant emotion possible? Australasian Journal of Philosophy, 91(3), 577-599.

Brady, M. S. (2010). Virtue, emotion, and virtue. Metaphilosophy, 40, 115-131.

Brady, M. S. (2013). Emotional insight: The epistemic role of emotional experience. Oxford: Oxford University Press.

Bratman, M. E. (1987). Intention, plans, and practical reason. Cambridge: Harvard University Press.

Cannon, W. B. (1929). Bodily changes in pain, hunger, fear, and rage. New York: Appleton.

Chisholm, R. (1957). Perceiving: A philosophical study. Cornell University Press.

Church, J. (1995). "L'émotion et l'internalisation des actions". In Paperman, P. \& Ogien, R. (eds.), La couleur des pensées, Raisons Pratiques no.6, Éditions de l'EHESS (pp. 219-236).

Colombetti, G. (2014). The feeling body: Affective science meets the enactive mind. Cambridge: MIT Press.

Cowan, R. (2016). Epistemic perceptualism and neo-sentimentalist objections. Canadian Journal of Philosophy, 46(1), 59-81.

Crane, T. (2009). Is perception a propositional attitude? Philosophical Quarterly, 59(236), 452-469.

D'Arms, J., \& Jacobson, D. (2000). The moralistic fallacy: On the 'appropriateness' of emotions. Philosophy and Phenomenological Research, 61(1), 65-90. 
D’Arms, J., \& Jacobson, D. (2003). The significance of recalcitrant emotion. In A. Hatzimoysis (Ed.), Philosophy and the emotions (pp. 127-135). Cambridge: Cambridge University Press.

Davidson, D. (1971). Agency. In A. Marras, R. N. Bronaugh, \& R. W. Binkley (Eds.), Agent, action, and reason (pp. 3-25). Toronto: University of Toronto Press.

De Sousa, R. (1987). The rationality of emotions. Cambridge: MIT Press.

Deigh, J. (1994). Cognitivism in the theory of emotions. Ethics, 104, 824-854.

Deonna, J. A. (2006). Emotion, perception, and perspective. Dialectica, 60(1), 29-46.

Deonna, J. A., \& Teroni, F. (2012). The emotions: A philosophical introduction. Abingdon: Routledge.

Deonna, J. A., \& Teroni, F. (2014). In what sense are emotions evaluations? In C. Todd \& S. Roeser (Eds.), Emotion and value (pp. 15-31). Oxford: Oxford University Press.

Dokic, J., \& Lemaire, S. (2015). Are emotions evaluative modes? Dialectica, 69(3), 271-292.

Döring, S. A. (2003). Explaining action by emotion. Philosophical Quarterly, 53(211), 214-230.

Döring, S. A. (2007). Seeing what to do: Affective perception and rational motivation. Dialectica, 61(3), 363-394.

Enç, B. (2003). How we act: Causes, reasons, and intentions. Oxford: Oxford University Press.

Frijda, N. H. (1986). The emotions. Cambridge: Cambridge University Press.

Frijda, N. H. (2007). The laws of emotion. Mahwah: Erlbaum.

Furtak, R. A. (2010). Emotion, the bodily, and the cognitive. Philosophical Explorations, 13(1), 51-64.

Furtak, R. A. (2018). Knowing emotions: Truthfulness and recognition in affective experience. Oxford: Oxford University Press.

Goldie, P. (2000). The emotions: A philosophical exploration. Oxford: Oxford University Press.

Greenspan, P. (1988). Emotions and reasons. New York: Routledge.

Harman, G. (1990). The intrinsic quality of experience. Philosophical Perspectives, 4, 31-52.

Helm, B. (2001). Emotional reason: Deliberation, motivation, and the nature of value. Cambridge: Cambridge University Press.

Howard, C. (2018). Fittingness. Philosophy Compass, 13, 11.

Jacobson, D. (2011). Fitting attitude theories of value. Stanford Encyclopedia of Philosophy. https://plato .stanford.edu/entries/fitting-attitude-theories/.

Kenny, A. (1963). Action, emotion, and will. Abingdon: Routledge \& Kagan Paul.

Kiesewetter, B. (2017). The normativity of rationality. Oxford: Oxford University Press.

Lord, E. (2018). The importance of being rational. Oxford: Oxford University Press.

Mele, A. (1992). Springs of action. Oxford: Oxford University Press.

Mendelovici, A. (2013). Pure intentionalism about moods and emotions. In U. Kriegel (Ed.), Current controversies in philosophy of mind (pp. 135-157). Abingdon: Routledge.

Milona, M. (2016). Taking the perceptual analogy seriously. Ethical Theory and Moral Practice, 19(4), $897-915$.

Milona, M., \& Naar, H. (2020). Sentimental perceptualism and the challenge from cognitive bases. Philosophical Studies, 177, 3071-3096.

Mitchell, J. (2019). Affective representation and affective attitudes. Synthese. https://doi.org/10.1007/ s11229-019-02294-7.

Moors, A., \& Boddez, Y. (2017). Author reply: Emotional episodes are action episodes. Emotion Review, 9, 4.

Müller, J. M. (2017). How to think of emotions as evaluative attitudes. Dialectica, 71(2), 281-308.

Müller, J. M. (2018). Emotion as position-taking. Philosophia, 46(3), 525-540.

Müller, J. M. (2019). The world-directedness of emotional feeling: on affect and intentionality. London: Palgrave Macmillan.

Müller, J. M. The spontaneity of emotion.

Mun, C. (2019). How emotions know: Naturalizing epistemology via emotions. In L. Candiotto (Ed.), The value of emotions for knowledge (pp. 27-50). London: Palgrave Macmillan.

Naar, H. (2016). Le caractère personnel des émotions. Revue philosophique de la France et de l'étranger, 141(2), 197.

Naar, H. (2017). Subject-relative reasons for Love. Ratio, 30(2), 197-214.

Naar, H. (2019). Emotion: Animal and reflective. The Southern Journal of Philosophy, 57(4), 561-588.

Pelser, A. C. (2014). Emotion, evaluative perception, and epistemic justification. In C. Todd \& S. Roeser (Eds.), Emotion and value (pp. 107-123). Oxford: Oxford University Press.

Roberts, R. C. (2003). Emotions: An essay in aid of moral psychology. Cambridge: Cambridge University Press.

Roberts, R. C. (2013). Emotions in the moral life. Cambridge: Cambridge University Press. 
Sartre, J. P., \& Frechtman, B. (1948). The emotions, outline of a theory. New York: Philosophical Library.

Scarantino, A. (2010). Insights and blindspots of the cognitivist theory of emotions. British Journal for the Philosophy of Science, 61, 729-768.

Scarantino, A. (2016). The philosophy of emotions and its impact on affective science. In M. Lewis, J. Haviland-Jones, \& L. F. Barrett (Eds.), The handbook of emotions (4th ed., pp. 3-48). New York: Guildford University Press.

Schachter, S., \& Singer, J. (1962). Cognitive, social and physiological determinants of emotional states. Psychological Review, 69(5), 379-399.

Solomon, R. C. (1973). Emotions and choice. Review of Metaphysics, 27(1), 20-41.

Svavarsdóttir, S. (2014). Having value and being worth valuing. Journal of Philosophy, 111(2), 84-109.

Tappolet, C. (2000). Emotions et valeurs. Paris: Presses Universitaires de France.

Tappolet, C. (2012). Emotions, perceptions, and emotional illusions. In C. Calabi (Ed.), Perceptual illusions: Philosophical and psychological essays (pp. 205-222). London: Palgrave.

Tappolet, C. (2016). Emotions, values, and agency. Oxford: Oxford University Press.

Publisher's Note Springer Nature remains neutral with regard to jurisdictional claims in published maps and institutional affiliations. 